\title{
THE SCARCITY OF FORESTERS
}

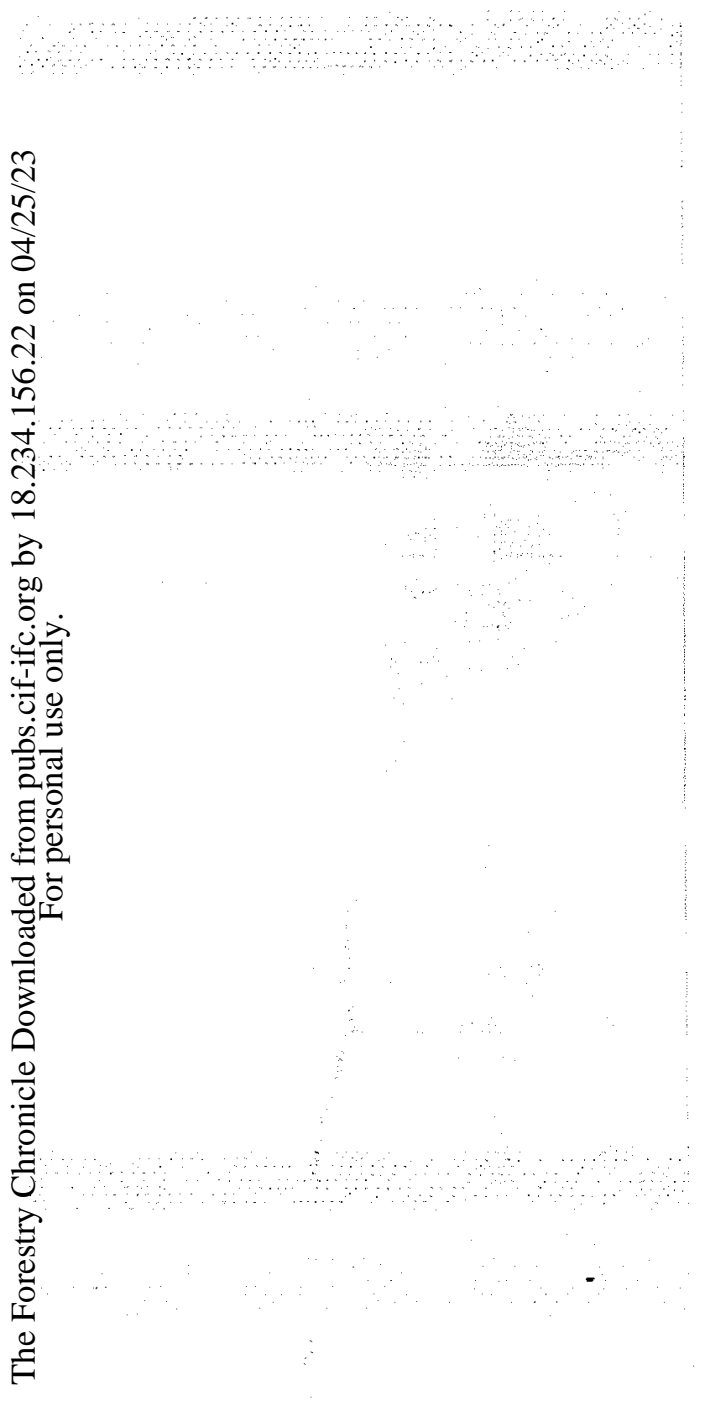

By R. C. Hosie

Faculty of Forestry, University of Toronto

T IS practically impossible to find an unemployed forester today. Whereas, five years ago, there were a number of foresters looking for work, now the governments and the companies are looking in vain for foresters. This scarcity is becoming a problem that must be of deep concern to all thinking foresters.

The ending of the war is expected to bring a national problem of such tremendous magnitude that plans to take care of the uncertain after-the-war period are already being thought out and widely discussed. Naturally those who are formulating the plans are confused, for no one can be certain of conditions then, and doubtless many of the projects that are now being proposed will never be put into operation. It is the belief of a great many individuals and groups that a program of conservation, well organized and carefully directed, will be of inestimable help in re-establishing men in civil life. We have vast natural resources and we are reminded that these re. sources are the nucleus of our social life. The forests are the most important of Canada's natural resources. Any program dealing with them would, therefore, include the forestry profession and demand an effort greater than ever before asked of it. Will the profession be equipped to cope with that undertaking?

The recent expansion in the industries that depend on the forests for raw materials is not alone responsible for the shortage of technically trained men. The call of the navy, the army, and the air force has been heard by a great many foresters and approximately one-fifth of the graduates in forestry of this Dominion are on active service. It is perhaps noteworthy that only a few of them have enlisted in the so-called Forestry Corps. That that branch of the army should have become so widely known, in both wars, as the Forestry Corps is unfortunate. It has led to the erroneous belief on the part of the public that foresters are not being loyal to their profession when so few of them are in it. The name Canadian Logging Corps would probably have been more descriptive.

The men who are going into active war services are mainly the younger men, the men who ten years hence would ordinarily be expected to assume responsibility in forestry affairs. From the Toronto school of forestry, with an annual enrolment of approximately forty, twenty-eight students have enlisted since the war started and before obtaining their degrees. The majority of these have been second and first year men. In the same period the school has graduated twenty young foresters, most of whom are now on active service or are on call. The loss of many young men or the delay in their graduation and the diversion of so many from the practice of their profession means that during the post-war period forestry affairs will be very largely directed by the older men. It means also that any rehabili. tation projects will be seriously handicapped by a shortage of trained personnel. We are going to find ourselves inadequately equipped to fulfill our proper part in the reconstruction of our civil life. 
Undoubtedly there is a scarcity of men in many divisions of our industrial and social life. The longer the war lasts the more serious will that scarcity become. That is one of the inevitable costs of war. It is surely a short sighted policy that fails to take account of the fact that our future welfare, though it depends first of all on winning the war, depends also on the proper use of our natural resources and that can never be attained if we are left unable to recover after the war. 